\title{
Energy matters in buildings: Individual and collective issues
}

\author{
Marie Denward \\ Interactive Institute Swedish ICT \\ Uppsala, Sweden \\ marie.denward@tii.se
}

\author{
Annelise de Jong \\ Interactive Institute Swedish ICT \\ Eskilstuna, Sweden \\ annelise@tii.se
}

\author{
Rebekah Olsen \\ Interactive Institute Swedish ICT \\ Eskilstuna, Sweden \\ rebekahlolsen@gmail.com
}

\begin{abstract}
The CELSIUS project is an EU funded demonstrator project that aims to facilitate the distribution, deployment and operation of smart district heating and cooling solutions across Europe, while at the same time supporting cities in the development of trustworthy, affordable and low carbon heat supply for citizens and businesses. In this paper we focus on the users of district heating systems and how they manage their energy uptake in apartment buildings in Gothenburg, one of the five European 'Celsius cities'. Parallel to the technical optimization of energy efficient systems, we are interested in social aspects of housing management that can explain the uptake of energy from a practice perspective. The technical approaches need to be completed with social research that tells the stories about people and companies introducing environmental technologies. We draw upon the social construction of thermal comfort. We aim to understand the uptake of energy as part of a practice of housing management, including both material and symbolic aspects. A case study is presented that provides insight into the social acceptance of a specific energy service geared towards energy efficiency in buildings in Gothenburg, called the Climate Agreement (CA). We have pointed out several barriers and drivers for social acceptance of the Climate Agreement; Complexity and awareness, Building personal relationship and trust, and Organisation and negotiation.
\end{abstract}

Keywords-interaction design; sustainability; district heating; social practices; smart cities; case study; housing cooperative; energy management

\section{INTRODUCTION}

Until recently, thermal comfort in the built environment was believed to be a purely physiological notion with standard temperatures pertaining to general comfort levels [1]. Consequently, buildings are designed to be monitored and maintained to certain standard conditions, while ignoring local climate and personal preferences. More recently however, it is argued within social science and HCI communities, that such standards are working against optimization of energy consumption [2]. Moreover, new norms and values are created through energy feedback mechanisms that favour certain types of behaviour that are in themselves perhaps not the best to support [3]. New socio-cultural understandings of thermal comfort are slowly becoming apparent, that are adaptable [4], and that are negotiable as such [5]. Other elements defining indoor climate than just temperature are also believed to be part of the mix, such as humidity and draught [6]. Adaptive environments where people can make themselves comfortable are even becoming part of the comfort standards albeit in a slow pace. Even more, there are certain socio-psychological factors that may play a role in defining people's comfort levels, such as social interaction, and being in control [7]. But how does more flexibility and control relate to current heating practices in apartment buildings, where people have a large variety of activities and presence? And how does this relate to energy uptake in terms of optimization and efficiency? These questions are picked up in our search for ICT support in current practices for energy management of apartment buildings in cities that are connected to the Celsius project. But before we present our work, we will give an overview of some of the key notions in this research that are important to point out and define our research goals.

\section{BACKGROUND}

The CELSIUS project is an EU funded demonstrator project that aims to facilitate the distribution, deployment and operation of smart district heating and cooling solutions across Europe, while at the same time supporting cities in the development of trustworthy, affordable and low carbon heat supply for citizens and businesses. Five European cities are 'Celsius cities'; Colon, Genoa, Gothenburg, London, and Rotterdam. When developing solutions for smart district heating and cooling the cities' different contexts from a variety of perspectives have to be taken into account. Geographical, historical, technical, geographical, social and cultural differences impose the development and implementation of solutions.

In this paper we focus on the end-users of district heating systems and how they manage their energy uptake in apartment buildings in Gothenburg. There are several techno-centred strategies deployed by energy companies in the project for optimizing the supply of energy, specifically hot water for heating. By limiting demand on peak moments during the day, morning and late afternoon, energy companies can optimize the production at those moments. Another strategy is to store heat in the building at other moments during the day, in order to provide stored heat during peak moments. Furthermore, 
temperature levels in buildings could be brought down overall to generate less demand and lower energy bills. Pricing is used here for steering demand on peak hours, but in Sweden this has mainly been used for steering individual electricity use, not for heating which is mostly often organised collectively in apartment buildings.

When working with energy consumption and demand issues, there is a focus on changing individual behaviour through addressing people's environmental values or offering financial incentives. However, changing energy consumption is not only an individual decision but is for a large part influenced by larger infrastructural or societal systems [8]. This is primarily the case when looking at reducing energy demand in apartment buildings like housing cooperatives in which owners democratically decide on the shared utilities. In Swedish housing cooperatives decisions are taken for the collective, since the board of a housing cooperative decides and manages the building for the common good of all its members. These are kind of 'political/policy' decisions, even on 'only' a building level, that give the individual members the right conditions for change/changing behaviour.

\section{A. District heating in Sweden}

Swedish district heating (DH) has a 60-years-long history. The development and extension has been dependent on political decisions and the surrounding world analysis. District heating has had a strong political support both on a governmental as well as municipal level [10]. As such the district heating industry has a monopoly position in Sweden, most suppliers are municipally owned, and if not, at least the municipal energy company owns the piping system. District heating has expanded greatly in recent years and is the dominant form for heating of multi-family apartment buildings and commercial premises in urban areas.

Gothenburg is the second largest city in Sweden, situated on the west coast, which means it has mild winters. It has a population of 550.000 people, and in the larger Gothenburg area live around 1 million people. The Gothenburg district heating system contains around $1300 \mathrm{~km}$ 's of piping. It is the second largest system after the Stockholm district. The energy supplier is the biggest supplier in the Gothenburg area and is owned by the Gothenburg municipality [11].

\section{B. Social practices and comfort}

Comfort is a complex notion, which is discussed in several disciplines. For instance, the basic need of warmth and shelter [6], but also in relation to eco feedback systems of energy consumption [e.g. 12]. However, apart from the current debate on their marginal effectiveness if at all [2], these systems are mostly geared towards addressing individual financial and environmental beliefs. Here, we refrain to our design research approach into socio-cultural aspects of sustainability [13]. Rather than putting emphasis on changing individual behaviour and accepting energy reduction strategies, we focus on how we can bring this discussion to another level. Perhaps by viewing it as a social practice, we can open up ways to contribute to the general dialogue on comfort expectations, and to work alongside with other actors in the complex infrastructural and utility provisioning of needs.
As such, previous research has indicated the need for a more systemic view of changing behaviour - and calls for different approaches than targeting individual behaviours such as a social practice approach [2]. Social practices regard people's activities and beliefs, that have grown and adapts over time by those who share these practices [14]. Thus, change is difficult to achieve from the outside, for instance by a designer, or by simply introducing new elements, such as an app to reduce energy consumption. However, in earlier research ways to open up practices of comfort in the home, and bathing were studied, that has provided us with some starting points for addressing energy consumption from a 'practice-centred' perspective [3].

Practice thinking can indeed take place at several levels. There are 'getting comfortable' practices at home, but there are also practices for maintaining a building's energy system. As such, our research aim is to understand how such practices have evolved and how the relations between elements of practices changed and influenced each other. So how does this help us in our search for optimization and adaptation? Here we aim to explore the relation between adaptive notions of comfort, and the current paradigm of changing individual behaviour and load control. Our aim is to explore ways forward for rethinking the individual-oriented energy feedback mechanisms and explore collective dialogue processes instead.

\section{METHOD}

Primary research was conducted by gathering information from different departments of the energy supplier about their customer services and marketing activities, and in particular about the Climate Agreement (CA). Secondary research consisted of interviews and a survey amongst different types of building owners in the Gothenburg area, owners both with and without a Climate agreement or other type of agreement. Here the overall aim was to understand how they manage and optimize the district heating system in their building, and to find out about their views on the different service agreements as well as which elements of the service agreement appealed to them.

\section{A. Semi-structured interviews}

Representatives of one large and one small private property owner, one middle-sized management company, and two housing cooperatives were interviewed. The respondents were selected because they had chosen a CA for optimization and management of their building. Only one large property owner was interviewed who had no CA. This company was chosen due to their own management and optimization of the heating system in their own apartment buildings through a system they had built up, without any involvement of the energy supplier. The interviews were set up to last for about $1.5 \mathrm{hrs}$ and contained open-ended questions on the type of building and surroundings, the type of residents, energy management in the building, the ways for communication between energy supplier and residents as well as between residents, and potential residential satisfaction surveys on these issues. The interviews were all attended by two researchers and audio-recorded. 


\section{B. Web survey}

Furthermore, a short web survey amongst 28 building owners was conducted and a few questions to follow up on the web survey answers conducted with a few respondents. We approached private building owners of apartment houses and housing cooperatives that had any type of service agreement (where the CA is one of five with service focus) and of those that did not have any agreement.

The first part of the web survey was about how they manage the heating systems in their building, if they had problems with this, and if so what type of problems. In the second part we asked about their experiences with the different agreements, both their own agreement and experiences in general with the service agreements. The web survey mainly consisted of multiple-choice questions. Some of them had the option for additional comments. In total there were 14 questions, where the first six questions asked about the background of the respondents. Eight questions dealt with the district heating of the building, and the service agreements.

\section{Analysis}

The interviews were analysed and summarized as 'stories' to show the various end users in terms of heating, and their experiences with the $\mathrm{CA}$. The researchers and associated project assistants to the Celsius project performed thematic analysis by going across the data of all the interviews, and themes evolved showing a number of common issues when stories were put next to each other. Also a number of quotes were taken from the data to highlight and illustrate the specific reason for having CA (or not having it) of each interviewee. These stories illustrate that they have to be interpreted within their context, but that they may serve as examples to illustrate the potential and importance of taking end-user related strategies into account for a holistic perspective of energy efficiency.

\section{RESULTS}

\section{A. The Climate Agreement (CA)}

This section starts with descriptions of the Climate Agreement, the customer segment that this agreement is tailored for, and elements relating to end user efficiency (acceptance). Thereafter the interview results are presented focussing on issues and problems with the CA, as well as results from the web survey.

The energy supplier offers five energy service agreements, ranging with the amount of service included. The Climate Agreement, also called Comfort Agreement, is the one that offers most services (Figure 1). Apart from these there is an agreement that only contains delivery of energy (without service). Delivery agreement is common for large companies that manage their own service needs.

We will commence by describing the different elements in the agreement, starting with those that are present in all types of agreements. Furthermore, we will describe other elements that are part of the Climate Agreement but that are not depicted in this figure.

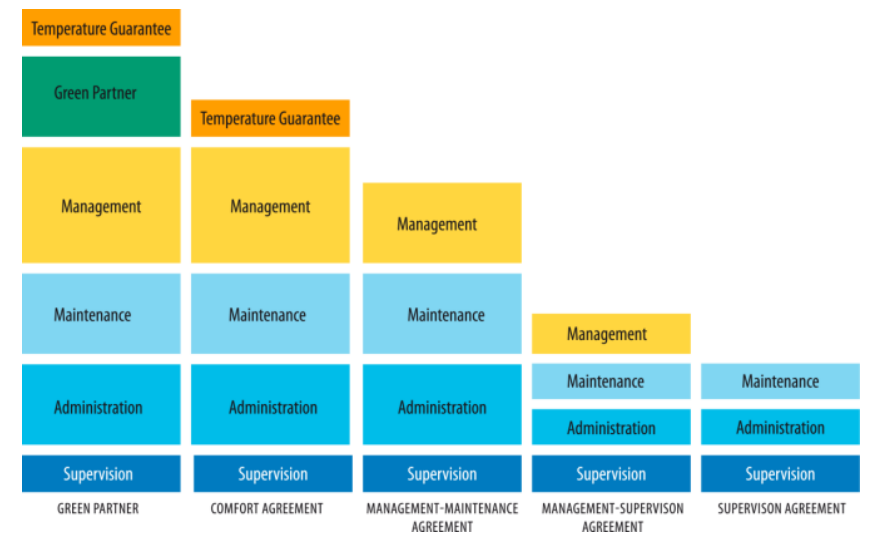

Figure 1. The figure shows the five energy service agreements offered by the energy supplier [15]. The only agreements that include a fixed/flat monthly price are Green Partner and Comfort Agreement (Climate Agreement). Green Partner is geared towards large/commercial property owners and requires a plan for how to reduce energy consumption by $25 \%$.

Supervision, Administration, Maintenance, Management \& Temperature Guarantee

All agreements contain supervision, administration and maintenance. Management is added for all but the most 'simple' one, and for the two most 'advanced' there is a temperature guarantee. The CA is offered to particular types of customers (see below). It has been available since 1995. The CA provides district heating and secures a standard indoor temperature (21C) throughout the year, offers personal service and various levels of technological investigations and analyses, improvement suggestions and measurement installations, maintenance and other solutions for the current complexity of optimizing the district heating systems in the customer's building(s). Important to note is that a temperature raise of one degree will increase the energy costs by another 5-7 \%. [16].

Before the contract is signed, the supplier starts to analyse the state of the building shell, and the radiator system. The supplier makes a diagnosis of existing temperature levels in the building(s) that tells if the radiator system is in balance or not. This is done through temporary installation of temperature sensors that stores data locally for 14 days. The sensors are collected and data retrieved in a computer program, and figures presented to the customer. Thus, the customer (and supplier) gets written proof if and where problems exist. Thereafter, the DH system is adjusted, either as part of the agreement and if so conducted by the supplier, or it is done by the owner before signing the contract. For example, ventiles may have to be installed in the DH system to optimize heat in the entire building/all apartments.

After signing the agreement the supplier installs Wi-Fi connected temperature sensors in a third of the apartments in the building(s) and that are connected to the larger computerized control system of the supplier. As such, the supplier can keep track on the entire building real time, and thus has a tool to meet the agreement requirements of 
maintaining a temperature of at least 21 degrees Celsius in the entire building (in all apartments). Investments like pumps, alarms, data system and computer have to be made, which are included in the agreement. When the CA period is completed the customer has paid off the costs and owns the entire system.

Two annual DH system check-ups are included as well as two personal annual information meetings with the customer (the company/the board of the housing cooperative) reporting all figures. The period it takes to adjust a building is around one year (four weather seasons). An agreement lasts between 3-5 years. Currently there are around $100 \mathrm{CA}$ contracts, an estimated $10 \%$ of all customers in the Gothenburg area. From the other $90 \%$ of the customers, around $50 \%$ could probably gain from getting a CA. The $90 \%$ could for example consist of larger building companies with their own personnel and technical systems to monitor and optimize energy usage. Others are large commercial buildings that have big ventilation systems with either a need of cooling instead, or where it could be difficult to keep 21 degrees Celsius. Around $40 \%$ of the $90 \%$ consists of housing cooperatives too small to gain economically from a CA.

\section{Fixed Price}

The costs of adjustments and optimization are built into the contract, and thus the costs broken down to be included in the monthly fixed rate. A fixed price offer is motivated by the large fluctuations during the year's four seasons and that the weather (cold) can differ largely from year to year in Sweden. These fluctuations make it very difficult to estimate energy costs for a building owner.

\section{Building Shell Analysis and Repair/Improvement}

Another service included is the mentioned analysis of the building shell where the supplier also gives advice on the status of the building shell to see if improvements like insulation, new windows or ventilation improvements are needed. The supplier calculates a prioritization order of improvements and repairs. The supplier acts as construction manager and engages sub contractors to conduct the construction work. If the customer, for financial reasons cannot pay for the technical installations needed as well as the construction work on the building shell, the supplier takes the costs, and includes them into the agreement, as have been mentioned with the improvements of the radiator system.

\section{The CA customer segment}

There are different types of building owners in the segment of the Climate Agreement. For our selection of the interview participants, we started out with defining different types of building organizations in the Gothenburg area and how they manage the heating system in their building. With help from the energy supplier we defined three types of actors for the research into $\mathrm{CA}$. These are also the common customer segment of the $\mathrm{CA}$ :
1. Private building owners, or property owners (freeholders), that own multiple-family apartments buildings (rental apartments) and have (among other things) the responsibility for managing the heating system.

2. Management organizations servicing different types of private building owners. Building owners can outsource certain activities to these organizations, like management of the heating system. Typically, they have an administrative and advisory role.

3. Housing cooperatives (in Swedish: bostadsrättsförening), the most prevalent CA customers, is one of the main forms of home ownership (apartment) in Sweden. A co-opt is a legal entity, usually a corporation, which owns real estate consisting of one or more residential buildings, a type of housing tenure. Members formally own the right to inhabit their respective apartments for an unlimited time period, a right that can be bought and sold on the open real estate market. The most common physical/legal form is a block of flats owned freehold by a cooperative. Each housing cooperative has its own bylaws. Members elect a board of directors (recruited among the members) that take on the responsibility of managing the cooperation during the upcoming year. This includes responsibility for managing the heating system as well as other services and maintenance issues for the building.

Not all building owners will gain from a CA, therefore the agreement is offered based on annual billing costs, building size, energy performance and efficiency. Cost reductions and energy savings can be made for owners with district heating energy costs exceeding 300000 SEK (around 32-33 000 EURO). The three mentioned customer types are prevalent, although the most common CA customer is a housing cooperative. The sales pitch for a housing cooperative is long; it may take between 6-12 months for the board to decide on a contract. There are several reasons for this. Its management (the board) consists of people living in the building (members of the co-opt), as mentioned, managing the building and its maintenance as a spare-time activity. They are commonly not particularly skilled in interest areas of real estate management. Also, the co-opt board has to prioritize between other (maintenance) costs and investments and compare with energy costs/savings that a CA could offer. All these circumstances make decisions take time. Each CA customer has an individual sales contact that manages all communication around the agreement and would answer any question the board/customer has.

\section{Elements relating to end user efficiency (acceptance)}

There are a number of benefits for the costumers of a CA. Energy costs for end users is calculated to decrease with between $15-50 \%$ depending on type, size and age of building. This is related both to the optimisation of the radiator system, improvement of the building shell as well as a possible 
decrease of indoor temperature. Connected to this are the improved temperatures in previously cold/warm apartment, thereby getting an even indoor temperature in the entire building.

With the monthly flat rate the customer can also control the energy costs, which is difficult to estimate otherwise depending on fluctuations in temperatures through out the year's seasons and from year to year.

Another customer benefit, that should not be underestimated, is the support the building owner (particularly for housing cooperatives without skilled management) gets in the complex process of energy saving improvements and optimizations such as (suggestions for and implementations of) technical improvements and installations of the building shell and the DH system.

To summarize, the agreement is a shared risk taking for both parties that usually pays off for both. The common story is that the agreement gives a lower price, and an even indoor temperature in all parts of the building. This can be compared with the former situation; without improvements and optimizations the temperature is commonly higher and uneven in building, and also fluctuating depending on outdoor weather/temperature. Thus, the agreement could be viewed as an acceptance issue, not a behaviour issue. In the long run, if for example a 2nd (or 3rd) CA is agreed upon, the energy costs should decrease due to the improvements.

\section{B. Interviews with Climate Agreement customers}

The interviews show that the reasons for choosing CA are mostly of a technical and financial character. However, as one private property owner mentioned, there is great value in being able to communicate a clear policy on the height of the temperature at the beginning of a new rental contract to establish the right expectations from tenants.
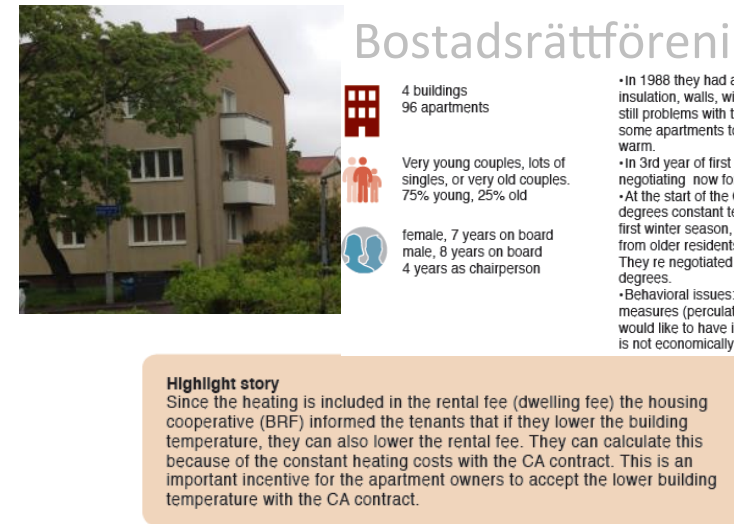

Figure 2. The figure shows the story from a housing cooperative indicating the importance of the CA as negotiation tool to discuss lowering the set indoor temperature.

We identified a variety of reasons why building owners need support with efficiency of their heating system, and how they are making their building(s) more efficient with the Climate Agreement.

\section{Complexity and awareness}

The different roles of the actors in the organisation of heating in buildings can work both positively and negatively. It is positive in case there is proper information between supplier and building owners, or from management company to building owners.

However, the housing cooperatives that had another service company than the supplier had no information on optimization and maintenance services from the energy supplier and were left with no support to deal with complexity of optimizing the heating system if they were not knowledgeable themselves. Even though both boards had technically skilled representatives of the management company, at least one of them did not get any support with how to go about improving the building shell and optimize them and make them environmentally better (insulation, ventilation, etcetera) or with choice of sub contractors to engage.

\section{Building personal relationship and trust}

As we heard in the story of one management company, who trusted the energy supplier well enough to provide advice to building owners about taking the agreement services. Especially those building owners that had signed a contract had built a personal relationship with contact persons from the energy supplier over time, even though they were quite sceptical from the start of the contract. But the housing cooperative customers with another service company than supplier suffered from lack of knowledge since they were not in direct contact with the supplier. They got reports directly from their own management company and did not know about service agreements from the energy supplier.

\section{Organization and negotiation}

The story of one of the housing cooperative showed the importance of illustrating the potential cost reduction as a result of the lower indoor temperature, see Figure 2. This housing cooperative was age-wise a mixture of residents but mostly younger couples and elderly people. Before the implementation of CA, the entire building was heated up to over 23 degrees Celsius, which was rather warm for younger couples who were away a lot, but preferred by the elderly who were often at home. With the implementation of the $1^{\text {st }} \mathrm{CA}$, the temperature was first lowered to 23 degrees, which in some cases led to more complaints from residents. In the $2^{\text {nd }} \mathrm{CA}$ the temperature was negotiated to 21 degrees, since even the lowering to 23 degrees (in the $1^{\text {st }}$ contract) resulted in a lower individual dwelling fee. This made it possible to rethink the height of the temperature again, and at the annual member meeting the unison decision of lowering the temperature to 21 degrees was taken.

The stories with the other two housing cooperatives (with CA), have provided us insight into ongoing efforts of owners to raise awareness for environmental efficiency. They worked with sorting garbage, reducing the opening of windows/doors 
and reducing the using of hot water. These efforts are examples of ways to involve and engage residents towards a more socially oriented type of behavior change, rather than reducing individual uptake.

The private property owner organized heating optimization separately from a service agreement, as the interview with large property owner and their optimization process show. In the case of this company, the owner has installed and maintained an ICT system consisting of permanently installed sensors and individual metering that allowed them to establish clear resident expectations on the temperature level and individual billing from the beginning. Also, this company included the service to visit residents (when complaining) in their homes and measure and give direct feedback on temperature levels. In other words, the company had a strategy/service to visit complaining residents in their homes, measuring and giving feedback on temperature levels.

\section{Summarizing interview results}

These are all different ways of how end users in the heating system are working with energy efficiency in apartment buildings and how the $\mathrm{CA}$ is taken up in their energy management practices. It should be seen as a first exploration in trying to open up customer dialogues and building up an understanding of heating practices and optimization of heating in buildings. However, one could ask since the CA is such a good offer why not all building owners - who meet the criteria - have signed this agreement? For this reason we have conducted a web survey with such building owners that provides insight into their interest and needs for service agreements for heating.

\section{Web survey with non-Climate Agreement customers}

28 individuals answered the web survey. They were all board members of housing cooperatives, varying in size between 14 and 517 apartments, in the Gothenburg area. We collected information on the board members' experiences of the heating in the buildings. The respondents seemed rather satisfied with the heating of their building/s, however they also responded that there was a problem with the heating and that members often complained about the indoor temperature. A majority $(65 \%)$ thought that heating costs were too high.

Only four of the cooperatives had a certain type of service agreement with the energy supplier. None of the housing cooperatives had the Climate Agreement. The reasons for not having any agreement did not seem grounded on knowledge of agreements and their contents, because seven out of twelve respondents answered that they didn't know or had not gotten information, as the reason for not selecting any service agreement. Only two respondents thought that it was not economically advantageous. According to the energy supplier's sales department, housing cooperatives consisting of more than around 20-30 apartments could benefit from having an agreement. As indicated before, a majority, 65\%, thought the costs for heating were too high, which probably could be lowered with any type of service agreement. Twelve cooperatives consisted of more than 28 apartments and were potential customers for Climate Agreement. This number could even be higher, since nine respondents skipped the question (Q3).

Even if respondents indicated that they had no service agreement we asked what respondents thought would be the most important element in an agreement. We connected the answers from question 8 to question 14. One would think that the costs would be more important, but guaranteed temperature and optimization were rated most important by altogether $56 \%$. So even if $77 \%$ thought that the indoor temperature was even, there were still members complaining about the temperature $(40 \%)$ or thought that there was a problem with the temperature (a third). So, the most important in a service agreement were the parts that are actually included in the Climate Agreement even indoor temperature and getting help to optimize the system, see Figure 3.

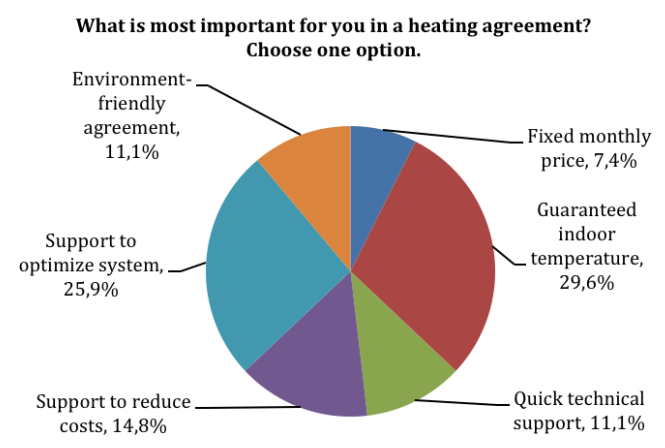

Figure 3: Web survey results question 14 (Q14): In a heating agreement, what is most important for you? Choose one alternative only.

\section{DISCUSSION}

In this study we looked at optimization of energy uptake in buildings that are organised by Swedish housing cooperatives. A housing cooperative is managed by a local board consisting of co-opt members. Typically, these members are not educated, or have low competence, on how to manage buildings. Our case study shows that there are problems and issues around the management and optimization of energy in these building(s). The energy supplier offers services for maintenance and optimization, like the Climate Agreement service that we studied in particular, but the housing cooperatives do not know enough about them to take action. Those who do have the CA generally understand their housing situation better and accept to get support to optimize the building. However, those that do not have the CA also generally have low or no knowledge and awareness about how to maintain and optimize energy uptake holistically, including how to improve the buildings shell etc. It is hard for non-experts to take action, and therefore these housing cooperatives choose to do 'nothing' - because it works 'rather good as it is'. In this way they have no tools to improve either building shells or how to take action to lower their energy consumption, and thus lower costs. We distinguished 
three main factors that influence the acceptance of CA; namely trust in the energy supplier, the complexity of the heating system, and finally to holistically manage and optimise the entire system of building shell and heating system.

Our research has focussed on the practice thinking that takes place at the collective level, practices for maintaining a building's energy system. The Climate Agreement is an offer to manage this and it has opened up collective discussions on current standards of (often uneven) indoor temperature levels in the housing cooperatives, and that, as we have shown, has most often meant a lowering of the temperature. But the CA also opened up collective discussions dealing with awareness of the entire building shell and the heating system, and how it could improve indoor temperatures, help housing cooperatives control heating costs and by optimizing the heating system and improving both that system and the building shell also decrease heating costs.

On request we presented our research findings to the management group of the supplier a few months after research was completed. Among other things we reported we concluded that the energy supplier's chosen path of offering holistic and individual energy services to the CA customers matched well with the results from a recent Swedish national research program Fjärrsyn [17]. Fjärrsyn had the goal to generate new knowledge for the Swedish district heating industries and with improved tools for competitive business models, showed the importance of and potential in improving customer dialogue and relationships. It concluded that the Swedish energy industry has to develop (among other things their customer relationships and services) to retain its strategic diligence and suggested a similar customer approach/business model that our studied energy supplier offers with their CA.

As a tool to manage and optimize energy uptake collectively in buildings, the Climate Agreement is particular to the Swedish cultural, social, technical and legal context. However, the energy supplier indicated that it is certainly possible to extrapolate the idea of providing this type of service to other customers. The energy supplier is now offering the CA as a concept to other Swedish cities (municipally owned energy companies), and possibly the offer could go to other European Celsius cities, as well as to other energy related companies that offer similar services. There are other examples illustrating how private property owners manage this type of service themselves, as the interview with large property owner and their optimization process show. In the case of this company, the owner has installed and maintained an ICT system consisting of permanently installed sensors and individual metering that allowed them to establish clear expectations from residents on the temperature level from the beginning, and to have individual billing for residents. Also, this company included the service to visit residents in their homes and measure and give direct feedback to residents on temperature levels.

Since the CA started already during late 90-ies, future research could go into exploring how issues of acceptance and changing practices of heating and optimisation have developed for housing cooperatives that have had the CA for longer time and determine effects. At present, we are studying similar housing conditions in other Celsius cities and how we can bring these learnings further. For instance, the Swedish CA approach is taken further in ongoing research in both Göteborg and the London area. For this purpose, we have designed and are conducting diary-supported dialogues with residents, and we are developing several design ideas on energy audit for diagnostics and understanding temperature levels in buildings, as a means for further actions for optimization.

\section{CONCLUSION}

This research aimed at understanding the uptake of energy as part of a practice of housing management, including both material and symbolic aspects. We presented a case study that provided insights to the social acceptance of a specific energy service geared towards energy efficiency in buildings in Gothenburg, called the Climate Agreement (CA). We have pointed out several barriers and drivers for social acceptance of the Climate Agreement; Complexity and awareness, Building personal relationship and trust, and Organisation and negotiation. The CA is an offer to manage energy efficiency in apartment buildings and it has opened up discussions on current standards of collectively set indoor temperature levels in the housing cooperatives, and that, as we have shown, has most often meant a lowering of the indoor temperature levels. But it also opened up discussions dealing with awareness of the entire building shell and the heating system, and how it could help housing cooperatives to control and decrease heating costs by optimizing the heating system and improving both this system and the building shell.

We have demonstrated how apartment building owners in Sweden concerned with energy management in their buildings differ to a large extent when it comes to their understanding of residents' thermal comfort, and knowledge on technical and organisational energy management of the building, resulting in less efficient buildings for those without relevant expertise. This means that optimization of heating by the energy supplier, i.e. on the delivery side is only part of the story, whereas the demand side has important potential in terms of energy savings, which is however hindered by lack of knowledge and expertise. The supplier offers this knowledge and expertise within different service agreements. The building owners, who do have a CA, have built up a good relationship with the energy provider over time, resulting in trust and regular communication on services that could support energy and cost efficiency, and thereby gained control and knowledge on energy management. However the building owners without CA are mostly not even aware of the availability of energy services, and they do not have the level of expertise needed for proper energy management. These building owners do not have little or no communications with the energy provider resulting in a lack of knowledge on energy management in the building, and thus in less energy efficient buildings. Here is a clear need for further attention as we have discussed with the energy supplier and which we are addressing in our current design research studies.

The CA can also be used to negotiate on indoor temperature between residents and building management of apartment buildings, and thereby fulfils another function as facilitator of dialogues on energy efficiency. Further research could include 
several perspectives on both the collective and individual matters of organizing energy matters in buildings. The individual behavior change of residents - for instance ventilation issues, and hot tap water consumption- is not addressed in CA. This is a form of optimization that is not necessarily needed for the optimization and/or the interviewed building owners address themselves in some cases, but it could be interesting to examine if the collective character of taking CA decisions might influence individual decisions also.

\section{ACKNOWLEDGEMENT}

This research is funded by EU grant, FP7-Energy smart cities 2012.8.8.2. Thanks also to Patrik Arvsell, Göteborg Energi for being available for questions on the technical systems.

\section{REFERENCES}

[1] Fanger, P.O., (1970). Thermal comfort analysis and applications in environmental engineering. McGraw-Hill, New York.

[2] Brynjarsdottir, H., Hakansson, M., Pierce, J., Baumer, E., Disalvo, C., and Sengers, P., (2012). Sustainably unpersuaded: How persuasion narrows our vision of sustainability. In Proceedings of the SIGCHI Conference on Human Factors in Computing Systems. ACM, 947-956.

[3] Kuijer, SC \& Jong, AM de, (2012). Identifying design opportunities for reduced household resource consumption: exploring practices of thermal comfort. Journal of Design Research, 10(1-2), 67-85.

[4] Brager, G; S. \& de Dear, R. (2000) A standard fro natural ventilation. ASHRAE Journal, October 2000.

[5] Shove, E., Chappells, H., Lutzenhiser, L. and Hakett, B. (2008) 'Editorial: Comfort in a lower carbon society', Building Research \& Information, Special Issue on Comfort in a Lower Carbon Society, Vol. 36, No. 4, pp.307-311.

[6] Bluyssen, Philomena M. (2009). The indoor environment handbook : how to make buildings healthy and comfortable. London, Earthscan.
[7] Bazley, Conne and Vink, Peter \& de Jong, Annelise (2014). Environmental comfort design considerations for future control room interiors. In: Proc. of the 5th International Conference on Applied Human Factors and Ergonomics AHFE 2014 (Eds. by T. Ahram, W. Karwowski and T. Marek), Krakow, Poland 19-23 July 2014, 19-23 July 2014.

[8] Power and Mont, (2011). Dispelling the myths about consumption behaviour. Knowledge Collaboration \& Learning for Sustainable Innovation ERSCP-EMSU conference, Delft, The Netherlands, October $25-29,2010$

[9] http://www.energikunskap.se/sv/FAKTABASEN/Vad-arenergi/Energibarare/Fjarrvarme/, accessed March 6, 2015.

[10] http://www.fjarrvarmensaffarsmodeller.se/pdf/historien.pdf, accessed March 6, 2015.

[11] http://www.goteborgenergi.se/Om_oss/Var_verksamhet, accessed, July 14, 2014.

[12] Froehlich, J., Findlater, L. and Landay, J. 2010. The Design of Ecofeedback Technology. Proceedings of the SIGCHI Conference on Human Factors in Computing Systems (New York, NY, USA, 2010), 1999-2008.

[13] de Jong, AM \& Maze, R (2010). Cultures of sustainability: ways of doing cooking. In R Weever \& J Quist (Eds.), Proceedings of ERSCPEMSU 2010 Conference - Knowledge Collaboration \& Learning for Sustainable Innovation ERSCP-EMSU 2010 Conference (pp. 1-25). Delft: TU Delft. (TUD)

[14] Shove, E., (2003). Comfort Cleanliness and Convenience: the Social Organisation of Normality. Berg, Oxford, UK.

[15] ]http://www.goteborgenergi.se/Foretag/Produkter_och_tjanster/Energitja nster/Energitjanstavtal, accessed September 2, 2014.

[16] Personal communication with Patrik Arvsell, February 10, 2014; July $10,2014$.

[17]

http://www.svenskfjarrvarme.se/Global/FJÄRRSYN/Rapporter\%20och \%20resultatblad/Rapporter\%20tvärvetenskap/2013/2013_7\%20Fjärrvär mens\%20affärsmodeller/Fjärrvärmens \%20affärsmodeller\%20sammanfa ttning.pdf, accessed November 10, 2014. 